\title{
PIEDRAS BEZOARES EN CONTEXTO: PRIMER ESTUDIO DE SU RELEVANCIA EN COMUNIDADES PREHISPÁNICAS DEL NOROESTE DE ARGENTINA
}

\author{
BEZOAR STONES IN CONTEXT: FIRST STUDY OF THEIR RELEVANCE IN \\ PREHISPANIC COMMUNITIES OF NORTHWESTERN ARGENTINA
}

\author{
Gabriel Miguez, ${ }^{1}$ Norma Nasif ${ }^{2}$, María E. Vides ${ }^{3}$, Mario A. Caria ${ }^{4 *}$ y Mónica Gudemos ${ }^{5}$
}

\begin{abstract}
En este artículo se profundiza el conocimiento acerca de una clase de objetos llamados piedras bezoares, mediante el estudio de los primeros ejemplares registrados en contextos arqueológicos del Noroeste argentino. Estos proceden de un montículo artificial del sitio Yánimas 1 (750-1200 d.C.), situado en la provincia de Tucumán (Argentina), y fueron estudiados desde un enfoque interdisciplinario con el fin de identificar el taxón que los produjo y explorar las prácticas en las que fueron utilizados. A partir de la caracterización formal y cristalográfica (difracción de rayos X) de tres ejemplares, y del examen de sus relaciones contextuales, se propone que las piedras bezoares analizadas son gastrolitos producidos por camélidos, que habrían sido usados en prácticas mágico-terapéuticas y depositados en el montículo como ofrendas. Estas interpretaciones fueron complementadas y reforzadas con datos de diversas fuentes (coloniales, etnográficas). Además, se presenta un nuevo fechado absoluto para este sitio.
\end{abstract}

Palabras claves: piedras bezoares, prácticas rituales prehispánicas, noroeste de Argentina.

This article expands our knowledge about bezoar stones by studying the first specimens recorded in archaeological contexts of the Argentine Northwest. These come from an artificial mound at Yánimas 1 site (750-1,200 AD), in Tucumán Province (Argentina), and were studied using an interdisciplinary approach to identify the taxon that produced them, and to explore the activities in which they were used. From the formal and crystallographic (X-ray diffraction) characterization of three bezoar stones and their contextual relationships, it is proposed that they are gastroliths produced by camelids, which would have been used in magic-therapeutic practices and deposited in the mound as offerings. These interpretations were complemented and reinforced by data from various sources (colonial, ethnographic). Additionally, a new absolute age for this site is presented.

Key words: Bezoar stones, prehispanic ritual practices, Northwestern Argentina.

En las últimas décadas, investigaciones etnográficas, etnohistóricas y arqueológicas aumentaron el conocimiento de las relaciones entre las comunidades aborígenes sudamericanas y la fauna de sus entornos, principalmente en relación con las actividades económicas o tecnológicas (Arenas 2003; del Papa 2010; Elkin y Rosenfeld 2001; Kent 1982; Mengoni Goñalons 1999). En cambio, el empleo de los animales (o sus productos derivados, como los sullus y los bezoares) en prácticas rituales y/o terapéuticas fueron menos explorados (Fernández Juárez 1998:56), sobre todo en contextos prehispánicos, debido a que son escasos los registros que permiten identificar estas prácticas en el pasado (Brosseder 2014:5; Corona Martínez 2008). En ese sentido, abordamos el estudio de uno de los materiales que puede indicar la existencia de esas actividades, como son las piedras bezoares producidas por animales.

Varias fuentes coloniales americanas revelan el interés que los bezoares tuvieron entre los aborígenes y los colonos europeos, tanto en el mundo andino (Acosta 1590; Calancha 1638; González Holguín 1989 [1608]:165) como en las tierras bajas orientales

I Instituto de Arqueología y Museo, Universidad Nacional de Tucumán. Miguel Lillo 205. S. M. de Tucumán (CP 4000). Tucumán, Argentina.

2 Instituto Interdisciplinario de Estudios Andinos, Universidad Nacional de Tucumán. Miguel Lillo 205. S. M. de Tucumán (CP: 4000). Tucumán, Argentina.

3 Fundación Miguel Lillo, Universidad Nacional de Tucumán. Miguel Lillo 205. S. M. de Tucumán (CP 4000). Tucumán, Argentina.

4 Instituto de Geociencias y Medioambiente, Universidad Nacional de Tucumán. CONICET. Miguel Lillo 205. S. M. de Tucumán (CP 4000). Tucumán, Argentina. mcaria1@yahoo.com.ar *autor correspondiente.

5 Programa de Estudios Antropológicos de la Música, Facultad de Artes, Universidad Nacional de Córdoba, Córdoba, Argentina.

Recibido: julio 2016. Aceptado: enero 2017.

http://dx.doi.org/10.4067/S0717-73562017005000019. Publicado en línea: 12-junio-2017. 
(Dobrizhoffer 1967 [1783]; Grenón 1922; Lozano 1941 [1733]; Renard-Casevitz et al. 1988:154). Además, cabe resaltar que las piedras bezoares tuvieron gran importancia en los Andes Centrales durante el Estado Incaico (Browman 2004; RenardCasevitz et al. 1988:154), y en ciertas zonas de Sudamérica se las ha registrado en contextos arqueológicos que superan los tres milenios de antiguiedad (p.ej. Messineo 2011; Prieto 2011).

En cambio, los registros más antiguos de piedras bezoares en todo el norte de Argentina datan del siglo XVIII (Dobrizhoffer 1967 [1783]; Lozano 1941 [1733]); mientras que, específicamente en la región del Noroeste argentino (NOA), solo existen algunos datos etnográficos que reportan su utilización (p.ej. Pérez de Nucci 2005). Dada la falta de información disponible acerca de esta clase de objetos en dicha región para épocas precolombinas, resulta relevante el aporte del presente trabajo, en el que abordamos el estudio de un conjunto de piedras bezoares halladas en el sitio Yánimas 1 (750-1200 d.C.), situado en el piedemonte meridional de la provincia de Tucumán. Aplicando varias líneas de análisis (formales-estructurales, composicionales, relaciones contextuales) intentamos responder a interrogantes como ¿de qué animales eran obtenidas? y ¿cuáles eran las prácticas en las que fueron empleadas? Asimismo, exploramos la importancia y el significado que habrían tenido estos bezoares para la comunidad que habitó este sitio entre los siglos finales del primer milenio d.C. y los iniciales del segundo.

\section{Precisiones Conceptuales y Generalidades Acerca de las Piedras Bezoares}

Los bezoares son compactaciones de diversos compuestos (pelos, fibras vegetales, cuerpos extraños, sustancias químicas, etc.) que se forman principalmente en las vías digestivas y excretoras de animales y seres humanos, como el sistema biliar, renal, urinal, salival, pancreático o gastrointestinal (Anzieta et al. 2008; Barroso 2014; MedinaPérez y Reyes López 1998). Pueden ser de consistencia blanda o constituirse en concreciones mineralizadas, formando verdaderas piedras o litos, cuya denominación dependerá del órgano donde se formaron (p.ej., gastrolitos, renalitos). Estas piedras bezoares, como se las conoce actualmente en el mundo occidental, se generan por litiasis: proceso que forma un sólido bioinorgánico en un sistema biológico mediante una reacción de precipitación en medio acuoso, generalmente regulado por la dinámica del organismo (Del Giúdice 2011; Simkiss y Wilbur 1989).

Varios animales producen estos biolitos y fueron muchas las sociedades, de diversas regiones del mundo, que los han empleado con distintas finalidades y los han denominado de diferentes maneras. Según Barroso (2013, 2014), el origen del término bezoar es asiático y derivaría de la antigua palabra persa padzahr ( pad = expulsa; $z a h r$ = veneno), que significa antídoto o contraveneno. Monardes (1565) señala que este término poseía variantes regionales: por ejemplo, los indios las nombraban bezar, los persas bezaar, los hebreos belzaar. Otras culturas denominaron a las piedras bezoares con otros vocablos, por ejemplo los griegos las denominaban alexipharmacum y los árabes hager.

En el antiguo imperio Persa se consideraba que estas piedras tenían propiedades mágicas y apotropaicas (Barroso 2014:78). Durante la época Medieval, la ciencia comienza a interesarse en estos objetos. En la literatura medicinal árabe han sido tratados desde el siglo VIII y en Europa fueron objeto de investigación desde el siglo XII, principalmente por las propiedades curativas que les han otorgado desde tiempos ancestrales (Barroso 2013, 2014).

Cuando los europeos llegan al continente americano y "descubren" las piedras bezoares producidas por varias especies de la fauna local, también se interesaron en ellas debido a la relevancia que le otorgaban las comunidades aborígenes (Millones Figueroa 2014). A partir de esos momentos, los tratados europeos de farmacología o farmacéutica (escritos entre el siglo XVI y el XIX) clasificaron a las "piedras bezoares" (Lapis bezoardicus off)-término con el que se referían específicamente a los gastrolitos de mamíferos rumiantes- como orientales (Lapis bezoar orientalis) a las producidas por rumiantes euroasiáticos (p.ej. Capra aegagrus), y occidentales (Lapis bezoar occidentalis) a las provenientes del tracto digestivo de mamíferos sudamericanos como camélidos (Lama glama y Vicugna vicugna) y cérvidos (Hippocamelus antisensis) (Jiménez 1838; Monardes 1574; Plans y Pujol 1870). Estos autores destacaron fundamentalmente el uso medicinal (como digestivos y contravenenos) de las piedras producidas por algunos camélidos y cérvidos, brindando información parcial tanto respecto de la diversidad de animales de los cuales se extrajeron, como de los usos y significados que le otorgaron 
las comunidades locales (Monardes 1574; Plans y Pujol 1870; entre otros).

Varias fuentes (coloniales, etnográficas, estudios etnohistóricos e históricos) revelan que los bezoares occidentales tradicionalmente utilizados por las comunidades originarias sudamericanas proceden de diversos animales, desde grandes mamíferos hasta peces de río (Casevitz et al. 1988:69, 79; Descola 1988:355; Dobrizhoffer 1967 [1783]; Grenón 1922; Lozano 1941 [1733]; Renard-Toledo 1997). Los más requeridos habrían sido los producidos por mamíferos herbívoros. Entre estos, la mayoría de los autores destacan a los que habitan las tierras altas andinas, como varias especies de camélidos (Lama glama, Vicugna vicugna, Vicugna pacos) y el cérvido taruca (Hippocamelus antisensis) (Acosta 1590; Brosseder 2014; Browman 2004; Flores Ochoa 1974; Grenón 1922; Hernández 2009; Latcham 1922; Lecoq y Fidel 2003; Loza 2007; Lozano 1941 [1733]; Millones Figueroa 2014; Monardes 1574; Pardal 1998 [1937]; Renard-Casevitz et al. 1988:69, 79). Pero también se ha resaltado la importancia de otros mamíferos que se distribuyen en el borde oriental andino, los piedemontes y las llanuras amazónica y/o chaqueña, como es el caso de otros cérvidos (Pudu sp.) (Grenón 1922) y los tapíridos (Tapirus terrestris y T. pinchaque) (Calancha 1638; Dobrizhoffer 1967 [1783]; Lozano 1941 [1733]; Renard-Casevitz et al. 1988:69; Toledo 1997). Otros casos son el ciervo de las pampas (Ozoteceros bezoarticus), que habita principalmente la llanura pampeana (Jackson 1987), y el guanaco (Lama guanicoe), especie de gran relevancia que habita varios hábitats del cono sur (Bullock 1929; Grenón 1922; Latcham 1922; Lozano 1941 [1733]; Pardal 1998 [1937]).

Acerca de las capacidades curativas de las piedras bezoares americanas, Latcham (1922:85) destaca sus propiedades absorbentes (vinculadas a su constitución porosa) y sus capacidades para neutralizar sustancias ácidas (relacionadas con sus composiciones químicas) como, por ejemplo, los venenos de serpientes y otros animales ponzoñosos. Estas cualidades podrían estar relacionadas con las aptitudes terapéuticas que les atribuyeron distintas sociedades en el pasado (y aún en el presente), como la de sanar males digestivos o la de ser efectivos contravenenos, mediante su aplicación directa, en infusiones o en combinación con otras sustancias (Browman 2004; Bullock 1929; Calancha 1638; Dobrizhoffer 1967 [1783]; Grenón 1922; Latcham
1922; Loza 2007; Lozano 1941 [1733]; Pardal 1998 [1937]; Toledo 1997; entre otros). Los jesuitas Lozano (1941 [1733]) y Dobrizhoffer (1967 [1783]) destacaron el uso medicinal de las piedras bezoares de animales que habitan las tierras altas y bajas del norte argentino (camélidos, tapires, cérvidos). Específicamente para el NOA, Pérez de Nucci (2005) resalta el valor medicinal que tradicionalmente han tenido los bezoares del guanaco en el área puneña (como febrífugos, astringentes y estimulantes) y las "piedras del anta" en ciertas zonas de Salta (para tratar males del corazón), generalmente mediante el raspado o molido de los bezoares para consumirlos en infusiones (Pérez de Nucci 2005:141). Pero, como señalan Browman (2004) y Loza (2007), estas piedras no solo se aprovecharon para la cura de varias afecciones físicas, sino también espirituales (susto, miedo, melancolía, males del corazón).

Cabe destacar que las comunidades aborígenes sudamericanas denominaron a las piedras bezoares con otros términos, que dependían de la lengua, la región y, probablemente, del animal del cual se extraían. En los Andes, uno de los vocablos más difundidos en el siglo XVI era el de illa o ylla (Guaman Poma de Ayala 1980 [1613]:491). Según González Holguín el vocablo quechua ayaylla refiere específicamente a "la piedra vezar" e Ylla refiere al rayo como deidad (junto al sol, las estrellas, etc.) evocada en ceremonias con sacrificios de llamas al pie del antiguo oráculo de Pachacamac, devastador y creador de la tierra (González Holguín 1989 [1608]:56, 10). Pero, a su vez, esta palabra tiene diferentes significados y sentidos según su combinación con otros vocablos, algunos de ellos con connotación sagrada. Por ejemplo, tener ylla es prestigio de cosa antigua, guardada; huaylla refiere a la pradera como parte de las denominaciones geográficas de marcada emoción telúrica y Munaylla nini significa bendecir o alabar a Dios, o a los santos (González Holguín 1989 [1608]:23, 27, 48). De todas maneras, dependiendo de la región andina considerada, el término illa podía comprender solo a bezoares o también a otras piedras de características particulares (Brosseder 2014).

Es importante resaltar que numerosas fuentes destacan la alta estima que estas piedras tenían entre los grupos andinos, porque se creía que daban buena suerte y prosperidad a su dueño y sus rebaños (Brosseder 2014:168-169; González Holguín 1989 [1608]:165; Hernández 2009; entre otros). Según Brosseder (2014:169), las yllas (bezoares 
de llamas y vicuñas) fueron objetos poderosos, y en particular las producidas por llamas eran reverenciadas para mejorar la fertilidad de estos animales. A mediados del siglo XVI, Cristóbal de Albornoz observó que en muchas zonas andinas donde se criaban llamas se extraían piedras bezoares del interior de estos animales ("illas llamas") y se las veneraba porque "creen que, mochando [adorando] a esta piedra, ninguna oveja abortará, ni subcederá mal a ninguno de sus ganados" (Albornoz 1989:165 [1568] citado en Duviols 1967:18; Hernández 2009:278). Por tanto, las piedras bezoares habrían tenido gran popularidad entre los pastores andinos. Con frecuencia eran mantenidas en sus viviendas junto con otros objetos como las conopas (figuras elaboradas en piedras pequeñas que representaban elementos importantes en la vida de estas comunidades, como la llama, el maíz, la papa o la hoja de coca) para el aumento del ganado (Brosseder 2014:169).

Pero su relevancia simbólica era aún de mayor envergadura, ya que, al parecer, se las empleaba en diversos rituales. La depositación de las piedras bezoares en las huacas, como ofrendas a los dioses, parece haber sido una práctica frecuente. Pedro de Osma reporta que estas piedras eran ofrecidas "a sus Guacas o Adoratorios, do tienen sus Ídolos, a los cuales ofrecen las cosas más preciosas que pueden haber, y así les ofrecen estas piedras, como cosa preciosa y de mucha estima, como ofrecen Oro, y plata, y joyas preciosas, y Animales y niños" (Monardes 1574:74). Otros autores sostienen que en los Andes Centrales estas piedras fueron "descubiertas en gran número bajo las huacas (Waka), particularmente en toda la región que va del Chinchay cocha a los Chanca" (Renard-Casevitz et al. 1988:69). Incluso es posible que estos objetos hayan tenido sus propios lugares de culto donde se las depositaba, conocidos como Illahuasi o casa de las piedras bezoares -ofrecidas a la divinidad del Rayo- (Hernández 2009). Según Brosseder (2014:170), durante la época colonial "las yllas y conopas estaban conectadas con las huacas en una variedad de formas, el trío de yllas, grasa, y hojas de coca era siempre una constancia en el culto a la huaca y en rituales de sanación".

Es evidente que desde épocas prehispánicas -al menos desde fines del estado Inca- las piedras bezoares fueron objetos de gran importancia en el mundo andino, porque además de amuletos para la prosperidad de los pastores y sus ganados, también se les ha adjudicado poderes mágicos, por ello se los ha empleado en diversos rituales, se los ha venerado y ofrendado a los dioses (Acosta 1590; Brosseder 2014; González Holguín 1989 [1608]; Hernández 2009; Monardes 1574; Renard-Casevitz et al. 1988). Debido a su relevancia medicinal y simbólica, fueron considerados preciados objetos de intercambio en el marco de redes de interacción interculturales, como por ejemplo las que se desarrollaron entre los Incas y comunidades de la vertiente oriental andina (Renard-Casevitz et al. 1988). Estos autores señalan que, entre los siglos XV-XVI, comunidades habitantes de la porción nororiental del imperio Inca (p.ej. los Chupachos, grupo cuyo modo de vida poseía una marcada influencia amazónica) intercambiaban y/o pagaban tributo a los Incas con varios objetos cúlticos, entre los que se destacaban las piedras bezoares de varios animales, como camélidos, tapires o peces (Renard-Casevitz et al. 1988:68-69, 79).

Es sugestivo también el hecho de que en la actualidad estos objetos continúen manteniendo una gran importancia simbólica, ya que se les sigue otorgando poderes mágicos y se siguen empleando en prácticas rituales. Registros etnográficos reportan que las piedras bezoares (y otras partes de las llamas) suelen ser utilizadas en las ofrendas que se realizan a los entes tutelares como los Apus o espíritus de las montañas, según rituales registrados en tiempos recientes (Flores Ochoa 1974; Lecoq y Fidel 2003). Incluso ciertas comunidades de pastores andinos consideran necesario, para mantener vigente el poder de estos objetos, revitalizarlos mediante determinadas prácticas rituales, porque si pierden sus fuerzas se tornan objetos peligrosos y negativos (Lecoq y Fidel 2003).

\section{Los Antecedentes Arqueológicos}

Uno de los registros de bezoares más tempranos proviene de la costa norte de Perú (sitio Pampas Gramalote, valle de Moche, una aldea de pescadores del período Inicial temprano: 1550-1250 a.C. En este sitio se halló un bezoar en un contexto funerario, cerca del cuello de uno de los individuos inhumados (Prieto 2011).

Un caso particular es el bezoar encontrado dentro de un atado o envoltorio (watasqa) de cuero de taruca registrado, bajo una piedra, en un abrigo rocoso en un lugar denominado Pallqa (400-1100 d.C.), situado en el valle de Amaguaya, La Paz, Bolivia (Capriles Flores 2002; Loza 2007). Loza 
(2007) sostiene que se trataría de un atado de remedios utilizados por un médico-religioso en tiempos del desarrollo de Tiwanaku. Dentro de este atado, la piedra bezoar (identificada como de camélido) se hallaba dentro de un estuche de cuero de vizcacha, asociado a un vellón de pelo de vicuña y a un cordaje terapéutico de alpaca y, según esta autora, pudo haber sido empleado para llevar a cabo rituales para la curación de enfermedades físicas y mentales (Loza 2007).

Politis et al. (2005:78) informan del hallazgo de un objeto caracterizado como "una estatuilla cilíndrica de forma fálica" decorado con incisiones lineales y en zigzag, asociado a restos óseos de mamíferos, aves y peces, pigmentos minerales, fragmentos cerámicos y macrorrestos vegetales carbonizados, acumulados en depósitos subsuperficiales registrados en el sitio Calera (ca. 3400-1750 a.p.), noroeste de Tandilia, provincia de Buenos Aires. Posteriormente Álvarez (2009) y Messineo (2011) determinaron que este artefacto fue elaborado a partir de un bezoar de Lama guanicoe. Cabe resaltar que se ha propuesto que dichas concentraciones resultaron de la depositación de vestigios derivados de actividades ceremoniales (rituales, festines) y ofrendas llevadas a cabo en el marco de congregaciones periódicas de comunidades aborígenes de la región Pampeana durante gran parte del Holoceno Tardío, y que la mencionada piedra bezoar tendría un alto valor simbólico (Messineo 2011; Politis et al. 2005).

Otro caso en la pampa argentina corresponde al Sitio 2 (fechado en la primera mitad del segundo milenio d.C.) de la localidad arqueológica de Paso Mayor, donde se registraron entierros primarios y secundarios de siete individuos asociados a fragmentos líticos, cerámicos, colorante, restos faunísticos, cuenta de valva y un bezoar (Bayón et al. 2010).

En relación con estos antecedentes, es admisible resaltar que en los trabajos que mencionan el taxón animal que produjo el bezoar reportado no se explica cómo se ha llegado a tal identificación, y en varios casos tampoco se precisan detalles de las características fisicoquímicas de los ejemplares reportados. De todas formas, aportan datos interesantes del empleo y significación que habrían tenido estas piedras en tiempos preincaicos. En síntesis, los registros prehispánicos más antiguos de piedras bezoares tienen entre 3000-3500 años a.p., y sus contextos de hallazgo los vincularían con prácticas rituales, ya que se los encuentran formando parte de ofrendas a difuntos, en depósitos de restos de actividades interpretadas como rituales o constituyendo parte de un equipo de implementos usados en curaciones "chamánicas". Por tanto, estos datos sugieren que la relevancia simbólica otorgada a estos objetos en el mundo andino y en otras áreas de Sudamérica fue una tradición milenaria.

\section{El Sitio Yánimas 1}

El sitio Yánimas 1, de donde provienen las tres piedras bezoares analizadas en este trabajo, se sitúa en la ribera del río Marapa, departamento La Cocha, en el piedemonte meridional de la provincia de Tucumán (Argentina). Se emplaza en un ambiente modificado de Selva Pedemontana de Yungas. Se caracteriza superficialmente por un conjunto de tres elevaciones monticulares (EM2, EM3 y EM4), alargadas (de 120-150 m de longitud y una altura promedio de $1,5 \mathrm{~m}$ ), que conforman una $U$ abierta, delimitando un espacio plano de alrededor de 1 ha. Los montículos y el espacio plano conforman el denominado Sector Central (SC) del sitio. En la mitad oeste de EM2 se eleva un cuarto montículo (EM1) de menor extensión pero de mayor altura (Figura 1). Se ha propuesto para este sitio la existencia de espacios domésticos y público/rituales, que conforman una ocupación datada entre 750-1200 años d.C., a partir de dos fechados radiocarbónicos (Miguez et al. 2014; Miguez y Caria 2015).

Las tres piedras bezoares fueron halladas en el montículo registrado como EM1, que se distingue de los demás tanto por su configuración externa (forma de cono truncado de base oval de aproximadamente $3 \mathrm{~m}$ de alto) como por su composición interna. En este montículo se recuperaron también numerosos fragmentos de vasijas decorados (en su mayoría corresponden a los estilos Aguada Negro Grabado y Ambato o Alumbrera Tricolor), no decorados, y cuatro tubos de pipas cerámicas, abundantes y diversos restos faunísticos -entre los que se destacan los bezoares y algunos huesos formatizados, como es el caso de un aerófono en fémur de ave-, carporrestos carbonizados, materiales líticos tallados y pulidos, dos pequeñas láminas de oro, cuentas de collar, dientes humanos, entre otros. Son recurrentes en su interior las concentraciones de sedimentos de color gris claro o blancuzco de aspecto ceniciento y la presencia de carbones de diversos tamaños. 


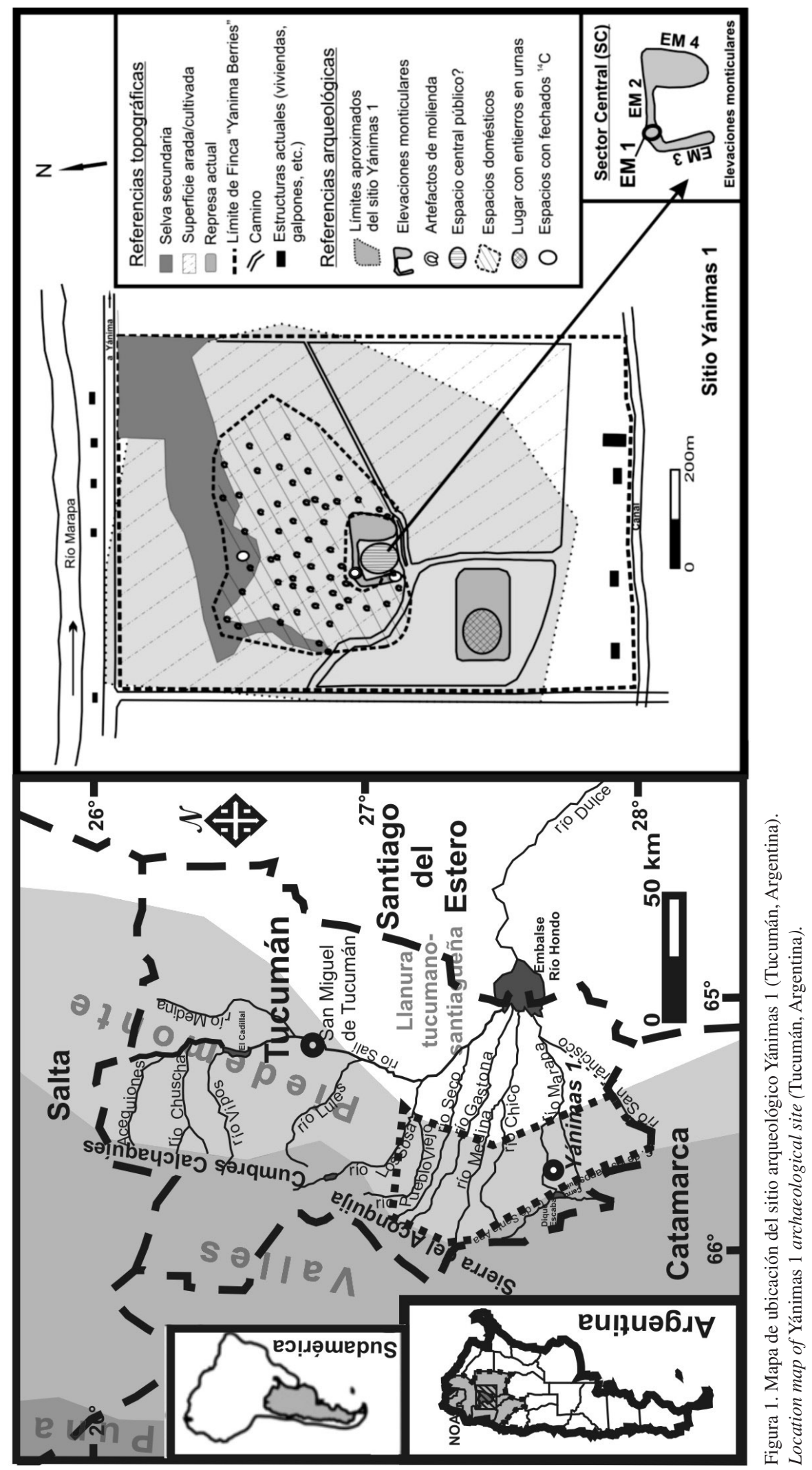


Por estas y otras propiedades del registro arqueológico, se ha sugerido que EM1 habría constituido un importante referente espacial desde el punto de vista ideacional, y que parte de los materiales allí depositados podrían constituir ofrendas y/o vestigios derivados de actividades simbólicas como ritos "chamánicos", ceremonias o festines comunitarios, entre otras, las que se habrían desarrollado en los alrededores de este montículo, como en el espacio plano central (¿plaza?) y en parte del montículo EM2 (Miguez y Caria 2015).

\section{Metodología Utilizada para el Análisis de los Bezoares}

La estrategia metodológica seguida para el estudio de los bezoares implicó un análisis formal y un estudio cristalográfico de estas concreciones. Así, para describir sus características externas (forma, color, aspecto superficial, marcas o huellas de uso) e internas (forma y color de las capas, grados de cristalización, espesores, forma y contenido del núcleo), los bezoares fueron observados a nivel macroscópico, microscópico y fotografiados. Las dimensiones fueron medidas con calibre metálico.

Para la identificación de la composición mineralógica de los bezoares se implementó un análisis cristalográfico -que brinda información de las estructuras internas cristalinas del estado sólidomediante difractometría de rayos $\mathrm{X}$ en muestras pulverizadas (método de polvo). Este análisis se basa en el supuesto de que cada sustancia mineral posee una estructura y simetría determinadas, que resulta en un patrón de difracción característico, permitiendo identificarlo con precisión. Las muestras fueron preparadas en el laboratorio de Sedimentología de la Fundación Miguel Lillo de Tucumán, cumpliendo varios pasos: (a) extracción de una fracción de material de cada ejemplar; (b) reducción de las muestras a polvo muy fino en mortero de ágata, hasta alcanzar la granulometría apropiada; (c) preparación no orientada de las muestras, prensadas sobre un portaobjetos. Luego las muestras fueron enviadas al Instituto de Investigaciones en Físico-Química de Córdoba (INFIQC, UNC), donde se realizaron las corridas de difracción de rayos X (DRX) Philips XPERT-PRO con ánodo de $\mathrm{Cu}$, obteniéndose el correspondiente difractograma para cada muestra.

Por último, se contextualizaron los bezoares a partir de la observación de las relaciones espaciales con otros materiales asociados en el montículo EM1. Asimismo, se analizaron estos objetos en relación con el registro arqueofaunístico del sitio. Los datos reunidos fueron comparados con la información obtenida de las diversas fuentes consultadas (etnográficas, etnohistóricas, museológicas, arqueológicas, biológicas).

\section{Resultados de los Análisis}

La mayoría de las fuentes bibliográficas consultadas que tratan acerca de piedras bezoares producidas por animales silvestres no informan de sus rasgos externos e internos, ni los ilustran. Por tanto, resulta necesario comunicar caracterizaciones más completas tendientes a la generación de una base de datos más sólida respecto de estos objetos. Esto facilitará la identificación de bezoares y sus posibles agentes productores, lo cual será de gran utilidad principalmente en el marco de estudios arqueológicos. En el siguiente apartado se procede a describir en detalle la morfología de los tres bezoares aquí analizados y, a continuación, se presentan los resultados de sus composiciones mineralógicas. Asimismo, los antecedentes arqueológicos acerca del tema no abundan en detalles de las relaciones contextuales específicas de estos objetos, y en muy pocos casos se brindan datos cronológicos precisos. Por ello, además del análisis de los bezoares en relación con sus restos arqueológicos asociados, también se presenta y discute la cronología absoluta de los mismos.

\section{Forma y estructura de los bezoares de Yánimas 1}

Los bezoares analizados (A, B y C; Figura 2) son cuerpos esféricos que en dos casos (A y C) se presentan achatados (de perímetro circular y sección subelíptica). Tienen superficie lisa a porosa y sus colores varían del pardo claro (bezoar A), pardo amarillento (bezoar B), al pardo-grisáceo (bezoar C). El bezoar B presenta una protuberancia que le confiere una forma subcónica (Figura 2B) y un aspecto resinoso que le da un brillo particular. Por su parte, el bezoar $\mathrm{C}$ presenta un sector aplanado - probablemente producido por el desgaste de una acción abrasiva- con una mancha levemente más oscura al color predominante de la pieza (Figura 2C: b, c). 

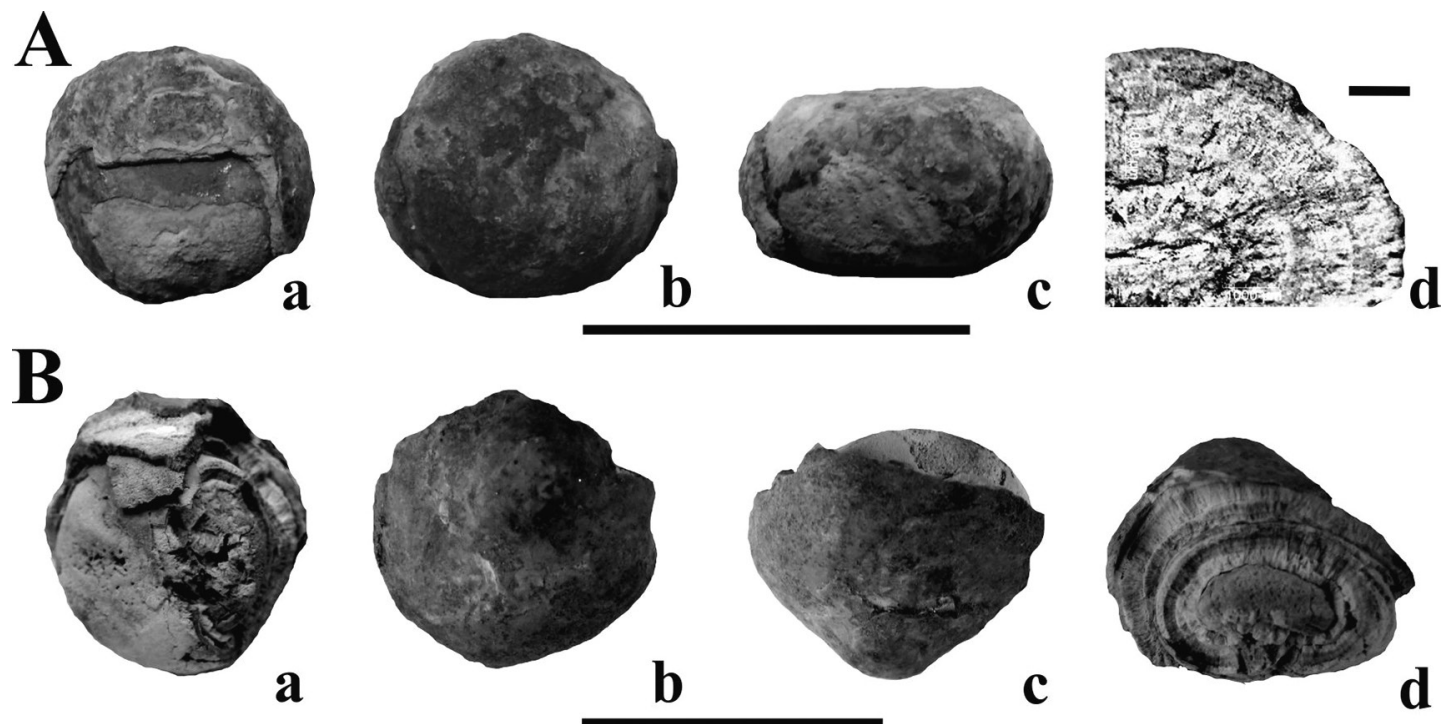

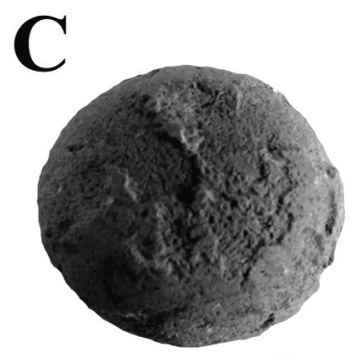

a

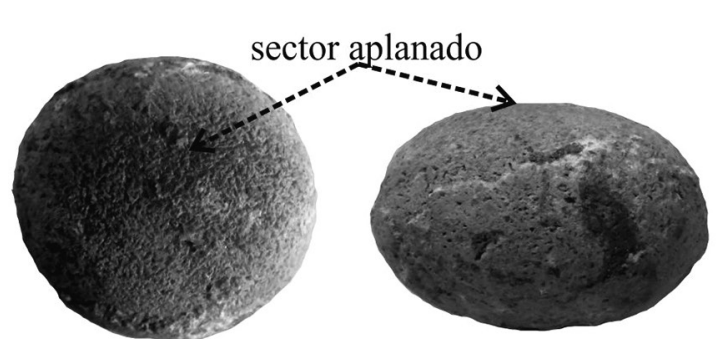

c

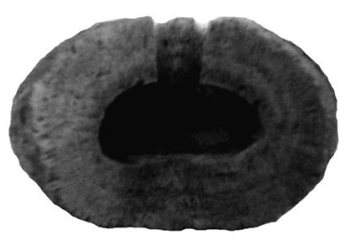

d

Figura 2. Piedras bezoares (A, B y C) analizadas.

Bezoar stones (A, B, C) analyzed.

La estructura interna de los bezoares consiste en capas sucesivas dispuestas concéntricamente alrededor de un núcleo. Las capas varían en color, conformación y espesor, desde claras a blanquecinas hasta oscuras amarronadas, desde cristalinas hasta compactas u opacas, y desde finas a gruesas (incluso una misma capa puede presentar diferencias en grosor). Las capas de mayor espesor están compuestas de cristales alargados dispuestos radialmente y las más finas y oscuras pueden representar líneas de crecimiento. Estas diferencias pueden reflejar distintos eventos de depositación durante la litiasis. El núcleo en los tres bezoares está hueco, ello implica que contuvo un material orgánico que se degradó. Incluso en el caso del núcleo del bezoar $\mathrm{B}$, la degradación del material orgánico puede haber disuelto parte del mineral que lo rodeaba, el que recristalizó rellenando parcialmente el hueco. Estos núcleos vacíos presentan variaciones en sus formas: en $\mathrm{A}$ es a modo de una ranura irregular alargada, en B es subcircular e invadida por material cristalino y en $C$ es una amplia abertura semicircular. Estas diferencias pueden estar relacionadas al tipo y forma del material que sirvió de núcleo. Mientras que el bezoar A pudo haberse formado alrededor de una fibra vegetal, los otros dos a partir de semillas (Orts et al. 2005) o pequeños bolos de fibras vegetal o animal (Latcham 1922). Estos datos nos sugieren que estos cálculos se habrían formado en el sistema digestivo de mamíferos herbívoros, a partir de restos vegetales no digeridos. A modo de ejemplo, Bullock (1929) reporta que una de las piedras bezoares de camélido que le obsequió un araucano contenía un palito como núcleo. 


\section{Análisis cristalográfico por DRX}

Los resultados del análisis cristalográfico realizados a los bezoares muestran que tienen una composición homogénea de fosfato anhidro de calcio y magnesio, Whitlockita $[\mathrm{Ca} 9 \mathrm{Mg}(\mathrm{PO} 3 \mathrm{OH})$ (PO4)6], un mineral de la clase de los fosfatos, que cristaliza en el sistema trigonal (R3c). Los picos diagnósticos de la Whitlockita han sido fácilmente identificables en los bezoares de Yánimas 1 (Figura 3). En el difractograma aparecen también picos característicos de cuarzo (sílice), que pueden deberse a contaminación desde el contexto edáfico del sitio.

El mineral identificado se corresponde con los compuestos determinados (fosfatos de calcio) para otros bezoares procedentes de rebaños actuales de camélidos que habitan las tierras altas andinas (Browman 2004). Asimismo, consideramos relevante la determinación cristalográfica de los litos producidos por organismos, ya que la sustancia predominante que los conforma puede relacionarse con el órgano donde se originó y el tipo de alimentación del agente productor. A modo de ejemplo, en gastrolitos y sialolitos predominan los minerales y en litiasis renales y vesiculares los derivados de la urea y el colesterol, respectivamente (p.ej. Grases et al. 2012; Lancina Martín et al. 2001). En tal sentido, la determinación de una sustancia mineral en los tres ejemplares es otro dato que aporta a su identificación como gastrolitos.

\section{Los bezoares de Yánimas 1 en relación contextual}

El montículo EM1, del cual proceden los tres bezoares analizados (A, B, C), fue excavado desde su cima, siguiendo niveles artificiales de 10 $\mathrm{cm}$. En términos generales, el análisis del registro arqueofaunístico (presente en toda la estratigrafía del montículo) indicó la presencia de una alta diversidad de animales, que abarcan todas las clases de vertebrados, además de algunos taxones de invertebrados. Los mamíferos son los mayormente representados en el variado espectro de taxones y más del $60 \%$ de este conjunto está constituido por los artiodáctilos de porte grande y mediano, incluyendo cérvidos como tarucas (Hippocamelus antisencis), corzuelas (Mazzama sp.) y camélidos como la llama (Lama glama). Respecto de las unidades anatómicas representadas, predominan los huesos de las extremidades de las patas (metapodios y falanges), presentándose algunos en posición de articulación (Nasif y Miguez 2014). Desde el punto de vista contextual, cabe señalar que parte de estos restos se han hallado en asociación con otros vestigios (orgánicos e inorgánicos), integrando conjuntos que habrían sido depositados en un mismo momento en cada caso. Los bezoares fueron encontrados en los primeros niveles del montículo y próximos a algunos de dichos conjuntos.

El bezoar A se halló en el nivel $2(10-20 \mathrm{~cm})$, donde se registraron restos cerámicos, faunísticos (huesos de artiodáctilos adultos y juveniles) y líticos (desechos de talla de cuarzo y esquisto); y en el nivel inmediatamente inferior se registró una extremidad de taruca (Hippocamelus antisensis) articulada y asociada a cerámica, desechos de talla de cuarzo y fragmentos de artefactos de molienda. El bezoar B procede del nivel $3(20-30 \mathrm{~cm})$, donde también se encontraron fragmentos cerámicos y huesos de fauna, restos líticos tallados y restos vegetales carbonizados, asociados a manchas de sedimento ceniciento; mientras en el nivel inferior se recuperó otra extremidad de taruca, completa y articulada, asociada a grandes tiestos, desechos de talla, cáscaras de huevos, huesos de otros animales y una lámina de mica.

Por último, el bezoar C proviene del nivel 5 (40-50 $\mathrm{cm}$ ), donde se recuperaron abundantes fragmentos cerámicos y huesos de fauna, principalmente de camélidos juveniles y adultos (entre ellos una falange de Lama glama), cérvidos, roedores grandes y pequeños, placas de armadillos, una falange ungueal y cáscaras de huevos de Rhea sp., restos óseos de otras aves y de peces, algunos con fracturas intencionales y termoalteraciones, destacándose la presencia del aerófono antes mencionado, elaborado en fémur de ave (Nasif y Miguez 2014), un diente humano y un artefacto (FNRC), un desecho de talla de cuarzo traslúcido y un fragmento de roca filoniana de cuarzo blanco, feldespato rosado y biotita negra. En posición relativamente cercana a dichos restos se encontraron dos fragmentos de pipas cerámicas (asociadas a huesos de aves medianas y una mandíbula de carnívoro chico) y, en la base del nivel superior, se halló una laminilla de oro cuya forma representa un rostro antropozoomorfo (Miguez 2014). De este nivel 5 de EM1, se obtuvo recientemente una datación radiocarbónica: $1.240 \pm 25$ a.p., UGAMS\#25525, colágeno de hueso, d13C $=-11,8 \%$ o. Los otros fechados publicados para Yánimas 1 (Miguez et al. 


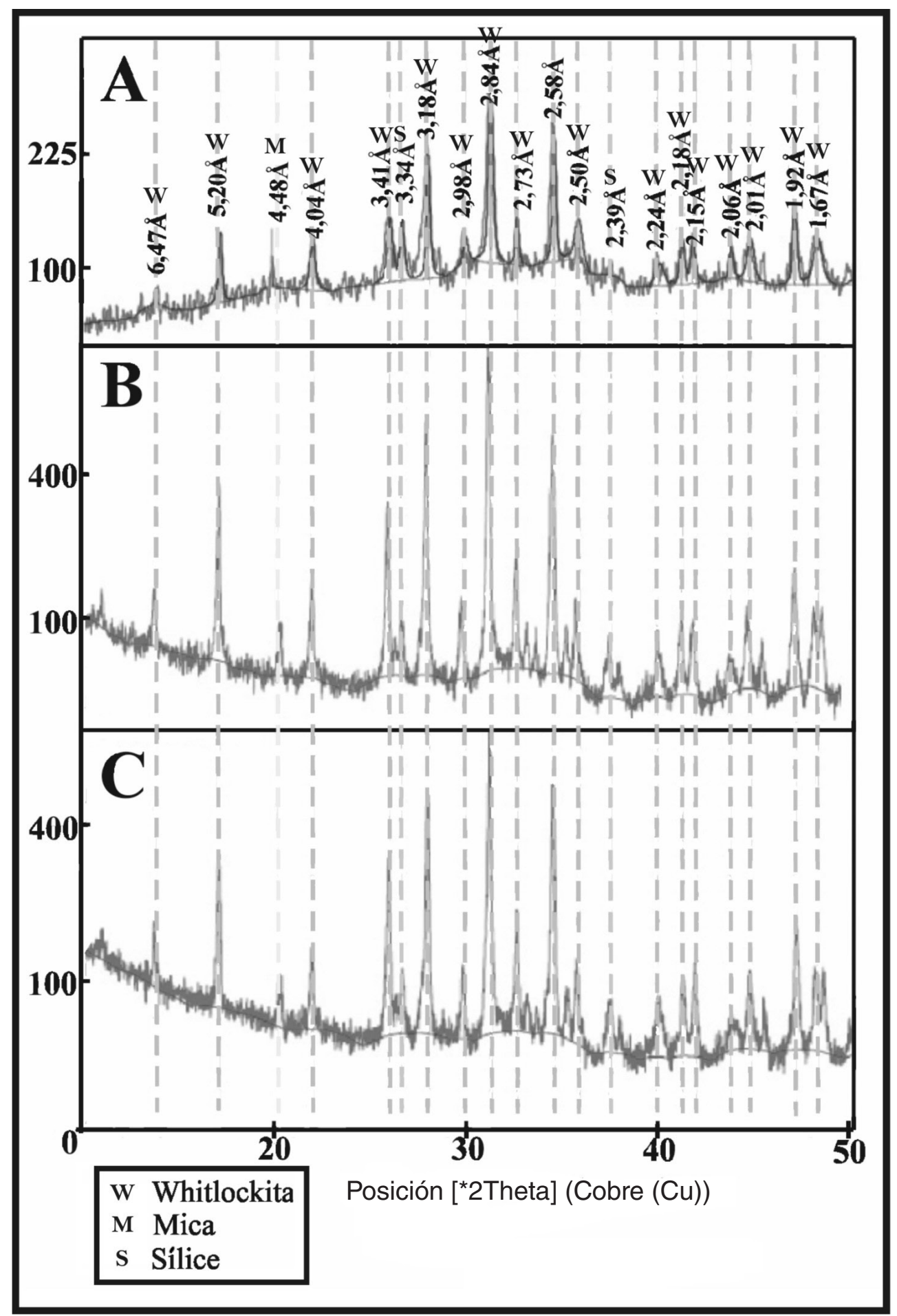

Figura 3. Difractograma de los bezoares analizados.

Diphractogram (RXD) of the bezoars analyzed. 
2014) son algo más tardíos y corresponden a otros sectores del sitio.

Los datos contextuales sugieren una interesante vinculación entre las extremidades articuladas de cérvidos (y sus restos asociados) y las piedras bezoares A y B, las cuales habrían formado parte de depósitos de conjuntos de objetos con un fin simbólico (posibles ofrendas). En el caso del bezoar $\mathrm{C}$, resulta sugestiva su cercana relación estratigráfica con el aerófono. Este último, por su forma, ha sido clasificado como un silbato tipo "mataco" (Miguez et al. 2013). Varios autores han destacado el empleo de estos silbatos en distintas actividades rituales "chamánicas", particularmente en comunidades aborígenes del Chaco sudamericano (Califano 1976; Dasso y Barúa 2006; Metraux 1944; Pérez Bugalló 1989). En tal sentido, el bezoar C y el silbato -y tal vez los fragmentos de pipas cercanos a ellos-podrían haber sido empleados en prácticas "chamánicas" antes de ser depositados en EM1.

\section{Acerca de la cronología absoluta del sitio y de las piedras bezoares}

Es preciso señalar que en anteriores publicaciones de Yánimas 1 (Miguez et al. 2013; Miguez 2014; Miguez y Caria 2015) se propuso una cronología absoluta para este sitio de ca. 900-1200 d.C. Dicha antigüedad estaba sustentada a base de los dos primeros fechados obtenidos para el sitio, ninguno de los cuales procedía del montículo EM1. Estos fechados fueron 960 \pm 70 años a.p. (LATYR-2185, Sector Norte del sitio, hueso humano, $90 \mathrm{~cm}$ de profundidad) y $1.060 \pm 60$ años a.p. (LATYR-2403, Sector Central, EM3, hueso de Lama glama, 30-40 $\mathrm{cm}$ de profundidad). Sin embargo, recientemente se han obtenido nuevas dataciones para el sitio (ambos con resultados muy similares) que proceden del montículo EM1, las que extenderían el límite inferior de la anterior cronología asignada al sitio unos 150 años de antigüedad, o sea, que ahora el sitio se ubicaría entre ca. 750-1.200 d.C. Pero además dichos fechados indican que el montículo EM1 habría sido construido en los momentos iniciales de la ocupación del sitio. Uno de los fechados procede de una muestra ósea animal recuperada en el nivel 5 (entre los 40-50 cm), cuyo resultado dio $1.240 \pm 25$ años a.p. (UGAMS25525, hueso, $\delta 13$ Ccol.: 18,23 \%o) (Martín Silva et al. 2016). La muestra datada corresponde al mismo nivel donde se halló uno de los bezoares analizados (bezoar C). A partir de esta datación se sugiere que las piedras bezoares fueron utilizadas al menos desde hace 1.200-1.300 años a.p. en el área de estudio, siendo este el registro más antiguo para todo el norte de Argentina.

\section{Discusión e Interpretaciones Acerca de la Identificación y el Uso de los Bezoares}

\section{Identificación del taxón que produjo los bezoares}

Tanto los atributos formales como la composición cristalográfica de estos bezoares permitieron determinarlos como gastrolitos producidos por camélidos sudamericanos, identificando así el taxón que los produjo. Además, la información respecto de los bezoares de otros taxones permite también reforzar estas interpretaciones. Así, los ejemplares de Yánimas 1 no corresponderían a cérvidos como la taruca (Hippocamelus antisensis), ya que se les atribuyen tamaños muy grandes y colores claros (Acosta 1590; Lozano 1941 [1733]). Tampoco serían de tapires (Tapirus sp.), porque las formas de sus cálculos son poligonales y su composición es de newberyta (fosfato de magnesio), según datos publicados por el Science Museum de Londres (http://collectionsonline.nmsi.ac.uk).

Asimismo, la comparación de los resultados obtenidos con los datos proporcionados por las fuentes consultadas de las características de las piedras bezoares de camélidos permite un acercamiento a la especie de origen. En este sentido, los gastrolitos de Yánimas 1 no corresponderían a guanaco (Lama guanicoe), debido a que mayormente se puntualizan tamaños mayores y formas frecuentemente ovales o cilíndricas levemente curvas (Bonacic 1992; Politis et al. 2005); y tampoco serían de vicuña (Vicugna vicugna), ya que estos tendrían tamaños mayores y notable finura (Lozano 1941 [1733]; Renad-Casevitz et al. 1988:154). Por último, la alpaca (Vicugna pacos) no puede descartarse completamente, ya que en el pasado su distribución biogeográfica incluía vastos sectores del área puneña del NOA (Bonacic 1991), pudiendo llegar sus gastrolitos al sitio Yánimas 1 mediante prácticas de intercambio, aunque hasta el momento no hay evidencia material que justifique esta inferencia.

Por tanto, si bien existen dificultades para determinar la especie que los produjo -dada la escasa e imprecisa información aportada por las fuentes consultadas-, se deduce que las piedras bezoares 
analizadas (pequeños cuerpos esféricos irregulares compuestos de fosfato de calcio) corresponderían a Lama glama.

\section{Origen y posibles usos de los bezoares}

Como se observa en la parte inicial de este trabajo, las fuentes coloniales y etnográficas consultadas no solo ponen de manifiesto la gran popularidad y relevancia que tuvieron las piedras bezoares en el pasado para las comunidades originarias que habitaron el mundo andino y las tierras bajas orientales, sino que también muestran la amplia variedad de usos y significaciones que se les ha atribuido a lo largo del tiempo y espacio, algunos de estos continúan en el presente. Asimismo, los pocos datos procedentes de contextos prehispánicos sugieren que parte de estas prácticas (ofrendas, depósitos rituales, usos mágico-terapéuticos) tienen larga data en ciertas áreas de Sudamérica, como es el caso de los Andes centromeridionales y la región Pampeana (Álvarez 2009; Loza 2007; Prieto 2011). Sin embargo, hasta este momento no existían registros de piedras bezoares en contextos prehispánicos del NOA y, en general, de todo el norte de Argentina. Por tanto, cabe preguntarse ¿cuándo y por qué fueron depositadas las piedras bezoares en EMI y en qué tipo de prácticas y con qué fin fueron usados?

En primer lugar destacamos que estos bezoares se encuentran asociados a restos de camélidos y de otros animales, lo que podría estar indicando alguna relación con acciones simbólicas tendientes a propiciar su reproducción o el éxito de su caza. Otro aspecto interesante para resaltar está relacionado con la presencia en el montículo EM1 de ciertos restos vinculados a los bezoares que pueden estar relacionados a ritos o ceremonias, como un aerófono de hueso y fragmentos de pipas. En el caso del primero, se trata de un silbato confeccionado en un fémur de ave rapaz (Miguez et al. 2013), muy similar a los pitos matacos cuyo uso ha sido ampliamente registrado en comunidades aborígenes del Chaco (matacos, lules), particularmente por "chamanes" en el contexto de actividades rituales (vuelos espirituales, sesiones terapéuticas), en las que frecuentemente se consumen plantas enteógenas como el cebil (Califano 1976; Dasso y Barúa 2006; Metraux 1944). Precisamente se han identificado microvestigios de cebil (Anadenanthera colubrina var. cebil [Griseb.] Altschul) y tabaco (Nicotiana spp.) en cuatro tubos de pipas hallados en EM1 (Martín Silva et al. 2016), dos de ellos cercanos al bezoar $\mathrm{C}$.

Estas evidencias permiten sugerir que los bezoares de Yánimas 1 pudieron haber sido empleados en el marco de actividades rituales "chamánicas", como puede ser el tratamiento o anulación de ciertos males espirituales o enfermedades físicas. En este sentido, la superficie levemente aplanada observada en el bezoar C (Figura 2Cb) podría estar indicando un uso específico, como puede ser el frotamiento sobre piel humana para la cura de determinadas afecciones o heridas, en tanto que la mancha observada en el mismo sector del objeto pudo haber sido producida por la acción de frotar la piel, o podría ser el producto de una alteración térmica debido al calentamiento previo del bezoar antes de su uso terapéutico. Si bien se necesitan más análisis para contrastar estas hipótesis, cabe señalar que Dobrizhoffer (1967:369 [1783]) ha registrado este tipo de prácticas en comunidades de las tierras bajas del norte argentino.

No es ilógico pensar que estos objetos pudieron haber sido empleados por "chamanes", dado que los bezoares han sido frecuentemente elegidos por estos agentes debido a su rareza y extrañeza (Müller-Ebeling y Rätsch 2011:121). Además no debe resultar extraño que uno de los bezoares haya sido encontrado asociado al mencionado silbato. En otras partes de los Andes, el "soplo chamánico" de sonido sibilante ha tenido y aún tiene un notorio poder dual y antagónico (Berenguer y Acevedo 2015), vale decir, que sirve tanto para curar como para causar enfermedades. Posiblemente ese poder, junto con el bezoar y el consumo de enteógenos en pipas, potenciaba la magia "chamánica" de quien manipulaba estos objetos.

Estas interpretaciones se ven reforzadas por hallazgos arqueológicos como el watasqa de Pallca (Bolivia), interpretado por Loza (2007) como un atado de remedios de un médico-religioso de la época de Tiwanaku, donde un bezoar y varios otros elementos (p.ej., tabletas de rapé, figurillas de camélido, minerales) habrían formado parte de la parafernalia mágico-religiosa de dicho individuo, constituyéndose en agentes de su sabiduría y de su poder para sanar. En otro contexto, en Ventilla, un pueblo ganadero del sur de Bolivia, se ha documentado la utilización de piedras bezoares de este tipo, llamadas jayantilla, después del sacrificio de una llama, para captar la energía vital de la 
víctima, estas piedras, al contacto con los órganos, se calientan rápidamente como si ellas captaran efectivamente la energía vital de la víctima $[\ldots]$ y pueden ser también utilizadas, una vez molidas, como remedio contra el miedo de los niños (Lecoq y Fidel 2003:28), lo que confirma, según los autores, su utilización ritual con fines curativos.

Por último, su presencia en el montículo EM1 puede estar indicando su depositación como ofrenda. $\mathrm{Al}$ respecto, ya hemos visto que varios autores han destacado la importancia simbólica que han tenido las piedras bezoares en las comunidades de los Andes centromeridionales, tanto en tiempos del Incario como durante la Colonia española, a tal punto que era una práctica común depositarlas en las huacas como ofrendas a los dioses o entidades tutelares (Flores Ochoa 1974; Hernández 2009; Monardes 1574; Renard-Casevitz et al. 1988:154).

\section{Consideraciones Finales}

En Sudamérica, el uso de piedras bezoares tiene unos tres mil años de antigüedad (o más), y eran populares en el mundo andino al momento de la llegada de los europeos a estas tierras. Sin embargo, a pesar de su relevancia, están escasamente representadas en los contextos prehispánicos. ¿Cuáles pueden ser las razones de esta situación? En primer lugar, hay que reconocer que, por lo general, los arqueólogos no están familiarizados con este tipo de objetos y suelen confundirlos como elementos constitutivos de los sedimentos (Corona Martínez 2008), razón por la cual muchas veces terminan siendo descartados durante las tareas de campo. Otras causas pueden vincularse con problemas en los métodos de registro arqueológico empleados, como las excavaciones con escaso nivel de detalle o el inadecuado cernido de los sedimentos.

Por sus características cristalográficas y sus relaciones con el contexto arqueológico de procedencia, sugerimos que los gastrolitos analizados fueron producidos por una especie de mamífero herbívoro, perteneciente a la Familia Camelidae (posiblemente Lama glama), y que, al menos en un caso, fueron utilizadas en prácticas rituales mágico-terapéuticas. Luego estos objetos habrían sido depositados en EM1 como ofrendas y, en el caso del bezoar $\mathrm{C}$, quizás también como parte de algún tipo de vestigio ritual. Pero sea cual fuere el rol que tuvieron estos bezoares en Yánimas 1, es bastante probable que hayan tenido un alto valor simbólico dado que han sido depositados en estrecha vinculación a vestigios (silbato, pipas, oro, fauna diversa y extremidades articuladas) que pudieron haber sido derivados de actividades litúrgicas (ritos "chamánicos", ceremonias comunitarias, actos ofrendatorios, etc.), y que junto con otros restos fueron acumulados y monumentalizados en un lugar (EM1) que habría tenido un destacado papel en la cosmovisión de la comunidad que habitó este sitio. Futuros estudios acerca de piedras bezoares, procedentes tanto de contextos arqueológicos como etnográficos, permitirán evaluar y ampliar los aportes realizados en este trabajo.

Agradecimientos: A la Cátedra de Bioarqueología de la Facultad de Ciencias Naturales e IML de la Universidad Nacional de Tucumán (UNT) por facilitar el material óptico. A los evaluadores anónimos que permitieron con sus sugerencias mejorar el trabajo.

\section{Referencias Citadas}

Acosta, J. 1590. Historia natural y moral de las Indias. Casa de Juan de León, Sevilla.

Álvarez, M. 2009. Análisis de los restos faunísticos del sitio Calera (Sierras Bayas, partido de Olavarría). Un aporte a su funcionalidad a través del estudio de los mamíferos. Relaciones de la Sociedad Argentina de Antropología 34:29-51.

Anzieta, J., O. Felmer, M. Gabrielli, F. Venturelli, G. Sánchez y C. Torrijos 2008. Obstrucción intestinal causada por Tricobezoar: Síndrome de Rapunzel. Revista Médica de Chile 136:1027-1030.

Arenas, P. 2003. Etnografía y Alimentación entre los TobaNachilamole\#ek y Wichí-Lhuku'tas del Chaco Central (Argentina). Buenos Aires.

Barroso, M. 2013. Bezoar stones, magic, science and art. Geological Society of London 375(1):193-207.
Barroso, M. 2014. The Bezoar Stone: a princely antidote. The Távora Sequeira Pinto Collection - Oporto. Acta de Historia de Medicina del Adriático 12(1):77-98.

Bayón, C., A. Pupio, R. Frontini, R. Vecchi y C. Scabuzzo 2010. Localidad arqueológica Paso Mayor: nuevos estudios 40 años después. Intersecciones en Antropología 11:115-128.

Berenguer, J. y N. Acevedo 2015. Tubos de hueso de ave como implementos chamánicos. Boletín del Museo Chileno de Arte Precolombino 20(1):51-72.

Bonacic, C. 1991. Características biológicas y productivas de los camélidos sudamericanos. Avances en Medicina Veterinaria 6(2). (9 de julio). http://web.uchile.cl/vignette/ avancesveterinaria/ CDA, (13 septiembre 2015). 
Bonacic, C. 1992. Cálculo abomasal en guanaco (Lama guanicoe) hallazgo de necropsia. Avances en ciencias veterinarias 7(1). (3 de febrero). http://www.avancesveterinaria.uchile.cl/index. php/ACV, (2 marzo 2015).

Brosseder, C. 2014. The power of Huacas: Change and Resistance in the Andean World of Colonial Perú. University of Texas Press, Texas.

Browman, D. 2004. Tierras comestibles de la Cuenca del Titicaca: Geofagia en la prehistoria boliviana. Estudios Atacameños 28:133-141.

Bullock, D. 1929. Stones from the stomach of a Guanaco. Journal of Mammalogy 10(2):170-171.

Calancha, F.A. 1638. Crónica Moralizada de la Orden de San Agustín en el Perú con Sucesos Exemplares Vistos en esta Monarchia. Biblioteca de la Universidad de Sevilla, Sevilla.

Califano, M. 1976. El chamanismo mataco. Scripta Ethnológica 3(2):7-60.

Capriles Flores, J. 2002. Intercambio y uso ritual de fauna por Tiwanaku: Análisis de pelos y fibras de los conjuntos arqueológicos de Amaguaya, Bolivia. Estudios Atacameños 23:33-51.

Corona Martínez, E. 2008. Las aves como recurso curativo en el México antiguo y sus posibles evidencias en la Arqueozoología. Archaeobios 2:11-18.

Dasso, M. y G. Barúa 2006. El devenir de bienes e instituciones: el cebil y el shamanismo wichi. Archivos del Departamento de Antropología Cultural 4(1):219-248.

Del Giúdice L.M. 2011. Litiasis. RevistaCiencias.com. Publicaciones Científicas. (11 de Noviembre). http://www. revistaciencias.com/publicaciones/EFkuVZEkklxLVhCxgO.php (13 diciembre 2016).

Del Papa, L. 2010. Revisión de la determinación de los materiales arqueofaunísticos provenientes del sitio Villa La Punta, Santiago del Estero. La Zaranda de Ideas 6:25-36.

Descola, P. 1988. La Selva Culta. Simbolismo y Praxis en la Ecología de los Achuar. Ediciones ABYA-YALA, Quito.

Dobrizhoffer, M. 1967 [1783]. Historia de los Abipones, Una Nación Ecuestre y Belicosa de Paracuaria, Tomo 1. Universidad Nacional del Nordeste, Resistencia.

Duviols, P. 1967. Un inédit de Cristobal de Albornoz: La instrucción para descubrir todas las guacas del Pirú y sus camayos y haziendas. Journal de la Société des Américanistes 56(1):7-39.

Elkin, D. y S. Rosenfeld 2001. Análisis faunístico de Pintoscayoc 1 (Jujuy). En El uso de los camélidos a través del tiempo, editado por G. Mengoni Goñalons, D. Olivera y H. Yacobaccio, pp. 29-64, Ediciones del Tridente, Buenos Aires.

Fernández Juárez, G. 1998. Los kallawayas: medicina indígena en los Andes bolivianos. Ediciones de la Universidad de CastillaLa Mancha Cuenca.

Flores Ochoa, J. 1974. Enqa, Enqaichu, Illa y Khuya Rumi. Aspectos mágico-religiosos entre pastores. Journal de la Société des Américanistes 63(1):245-262.

González Holguín, D. 1989 [1608]. Vocabulario de la Lengua General de todo el Perú llamada Lengua Qquichua o del Inca. Universidad Nacional Mayor de San Marcos, Lima.
Grases, F., A. Costa-Bauza, R. Prieto, A. Servera, E. Pieras y J. Ferrutxe 2012. Cálculos renales raros. Actas Urológicas Españolas 36(6):383-384.

Grenón, S. 1922. Piedras Bezares. Estudios históricos coloniales. Revista de la Universidad Nacional de Córdoba 5(6-7):281-302.

Guaman Poma de Ayala, F. 1980 [1613]. El Primer Nueva Crónica y Buen Gobierno. Editorial Siglo Veintiuno, México.

Hernández, N. 2009. El Conquistador Infiel. Las formas de Santiago Apóstol en los Andes Centrales durante la Colonia. Maguaré 23:265-301.

Jackson, J. 1987. Ozotocerus bezoarticus. Mammalian Species 295:1-5.

Jiménez, M. 1838. Tratado de Materia Farmacéutica. Imprenta de D. Sanchiz, Madrid.

Kent, J. 1982. The Domestication and Explotation of the South American Camelids: Methods of Analysis and their Application of Circum-Lacustrine Archaeological Sites in Bolivia and Peru. Tesis Doctoral. St. Louis, Washington University, USA.

Lancina Martín, J.A., R. Vila Passols, J. Lázaro Castillo, F. Grases Freixedas y M. Arrabal Martín 2001. Análisis del cálculo en la era de la litotricia extracorpórea. Actas Urológicas Españolas 25(6):462-479.

Latcham, R. 1922. Los Animales Domésticos de la América Precolombina. Museo de Etnología y Antropología, Santiago.

Lecoq, P. y S. Fidel 2003. Prendas simbólicas de camélidos y ritos agro-pastorales en el sur de Bolivia. Textos Antropológicos 14(1):7-54.

Loza, C. 2007. El atado de remedios de un religioso/médico del periodo Tiwanaku: miradas cruzadas y conexiones actuales. Bulletin de l'Institut Français d'Études Andines 36(3):317-342.

Lozano, P. 1941 [1733]. Descripción Corográfica del Gran Chaco Gualamba. Universidad Nacional de Tucumán, San Miguel de Tucumán.

Martín Silva, V., G. Miguez y M. Korstanje 2016. Análisis de microvestigios en pipas procedentes de ocupaciones prehispánicas de las selvas meridionales del Noroeste argentino. El caso de Yánimas 1. Estudios Atacameños, en prensa.

Medina-Pérez, M. y A. Reyes López 1998. Bezoares gástricos asociados a obstrucción por heterotopía pancreática pilórica. Revista Española de Patología 31(2):137-140.

Mengoni Goñalons, G. 1999. Cazadores de Guanacos de la Estepa Patagónica. Sociedad Argentina Antropología. Buenos Aires.

Messineo, P. 2011. Investigaciones arqueológicas en la cuenca superior del Arroyo Tapalqué. Un modelo de ocupación humana para el centro de la subregión Pampa Húmeda durante el Holoceno tardío. Intersecciones en Antropología 12:275-291.

Metraux, A. 1944. Estudios de etnografía chaquense. Anales del Instituto de Etnología Americana 5:263-311.

Miguez, G. 2014. Brillan en la selva. Contexto y análisis técnico de objetos de oro hallados en un sitio prehispánico del piedemonte meridional tucumano. Relaciones de la Sociedad Argentina de Antropología 39:277-284. 
Miguez, G. y M. Caria 2015. Paisajes y prácticas sociales en las selvas meridionales de la Provincia de Tucumán $\left(1^{\circ}\right.$ milenio d.C.). En Crónicas Materiales Precolombinas. Arqueología de los Primeros Poblados del Noroeste Argentino, editado por M.A. Korstanje, M. Lazzari, M. Basile, M.F. Bugliani, V. Lema, L. Pereyra Domingorena y M. Quesada, pp. 111-148. Sociedad Argentina de Antropología, Buenos Aires.

Miguez, G., M. Caria y M. Pantorrilla Rivas 2014. Las estatuillas cerámicas en la vida de las poblaciones prehispánicas de las selvas subtropicales meridionales del NO Argentino. Revista Española de Antropología Americana 44:39-63.

Miguez, G., N. Nasif, M. Gudemos y S. Bertelli 2013. Aves, sonidos y chamanes. Estudio interdisciplinario de un instrumento musical óseo procedente de una ocupación prehispánica de las selvas meridionales del noroeste de Argentina. Anales del Museo de América 21:137-168.

Millones Figueroa, L. 2014. La Piedra Bezoar: una maravilla natural en el Nuevo Mundo. Hispanofila 171. http://thefreelibrary. com/The+bezoar+stone\%3anew +world (7 diciembre 2016).

Monardes, N. 1574. Historia Medicinal de las Cosas que se Traen de Nuestras Indias Occidentales. Casa de A. Escrivano, Sevilla.

Müller-Ebeling, C. y C. Rätsch 2011. Tiere der Schamanen. Krafttier, Totem und Tierverbündete. AT-Verlag, Aarau.

Nasif, N. y G. Miguez 2014. La fauna relacionada a una comunidad prehispánica del piedemonte meridional de la Provincia de Tucumán (Argentina). Folia Histórica del Nordeste 22:203-232.

Orts, J., L. Morell, J. Camps, M. Traba, A. Belenguer y A. Guerrero 2005. Enterolitiasis múltiple, coexistiendo con litiasis biliar y vesical, asociada a adenocarcinoma de colon. Anales de Medicina Interna 22(5):227-230.

Pardal, R. 1998 [1937]. Medicina Aborigen Americana. Ed. Renacimiento, Sevilla.

Pérez Bugallo, R. 1989. Los silbatos chaquenses. Relaciones de la Sociedad Argentina de Antropología 17:87-97.

Pérez de Nucci, A. 2005. La medicina Tradicional del Noroeste Argentino: Historia y Presente. Ediciones del Sol, Serie Antropológica, Buenos Aires.

Plans y Pujol, F. 1870. Lecciones de Farmacozoología y de Mineralogía y Geología Farmacéuticas. Editorial Niubó, Barcelona.

Politis, G., P. Messineo, C. Kaufmann, M. Barros, M. Álvarez, V. Di Prado y R. Scalise 2005. Persistencia ritual entre cazadores recolectores de la llanura pampeana. Boletín de Arqueología 9:67-90.

Prieto, G. 2011. Cuando los dioses ganaron sus colmillos. 76th Annual Meeting de la Society for American Archaeology. Sacramento, California.

Renard-Casevitz, F., T.H. Saignes y A. Taylor 1988. Al Este de Los Andes. Relaciones entre Sociedades Amazónicas y Andinas entre los Siglos XV y XVII. Editorial ABYA-YALA, Quito.

Simkiss, K. y K. Wilbur 1989. Biomineralization. Cell Biology and Mineral Deposition. Academic Press, San Diego.

Toledo, A. 1997. Etnomedicina andina en el Ecuador: El uso de animales silvestres con fines curativos, en especial del tapir de montaña (Tapirus pinchaque). $49^{\circ}$ Congreso Internacional de Americanistas. (Julio). fttp://ftp.naya.org.ar/congresos/ contenido/49CAI/Toledo.htm., (3 agosto 2015). 
